Dear author,

Please note that changes made in the online proofing system will be added to the article before publication but are not reflected in this PDF.

We also ask that this file not be used for submitting corrections. 
Original article

\title{
Structural and metabolic differentiation between bipolar disorder with psychosis and substance-induced psychosis: An integrated MRI/PET study
}

\author{
Q1 A.C. Altamura ${ }^{a}$, G. Delvecchio ${ }^{b}$, G. Marotta ${ }^{c}$, L. Oldani ${ }^{a}$, A. Pigoni $^{a}$, V. Ciappolino ${ }^{a}$,

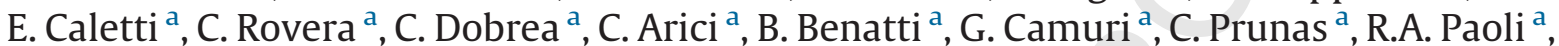 \\ B. Dell'osso ${ }^{\mathrm{a}, \mathrm{d}}$, C. Cinnante ${ }^{\mathrm{c}}$, F.M. Triulzi ${ }^{\mathrm{c}}$, P. Brambilla $^{\mathrm{a}, \mathrm{e}, *}$ \\ a Department of Neurosciences and Mental Health, Institute of Psychiatry, Fondazione IRCCS Ca' Granda, Ospedale Maggiore Policlinico, University of Milan, \\ Milan, Italy \\ Q2 ${ }^{\mathrm{b}}$ Scientific Institute IRCCS “E. Medea”, Italy \\ ${ }^{\text {c }}$ Department of Services, Neuroradiology Unit, Nuclear Medicine Unit, Fondazione IRCCS Ca' Granda Ospedale Maggiore Policlinico, Milan, Italy \\ ${ }^{\mathrm{d}}$ Department of Psychiatry, Bipolar Disorders Clinic, Stanford University, CA, USA \\ e Department of Psychiatry and Behavioural Neurosciences, University of Texas at Houston, Houston, TX, USA
}

\section{A R T I C L E I N F O}

\section{Article history:}

Received 23 May 2016

Received in revised form 20 September 2016

Accepted 24 September 2016

Available online $\mathrm{xxx}$

\section{Keywords:}

Bipolar disorder

Substance-induced psychosis

Magnetic resonance imaging (MRI)

Positron emission tomography (PET)

Gray matter

Cerebral metabolism

\begin{abstract}
A B S T R A C T
Background: Bipolar disorder (BD) may be characterized by the presence of psychotic symptoms and comorbid substance abuse. In this context, structural and metabolic dysfunctions have been reported in both BD with psychosis and addiction, separately. In this study, we aimed at identifying neural substrates differentiating psychotic $\mathrm{BD}$, with or without substance abuse, versus substance-induced psychosis (SIP) by coupling, for the first time, magnetic resonance imaging (MRI) and positron emission tomography (PET).

Methods: Twenty-seven BD type I psychotic patients with $(n=10)$ or without $(n=17)$ substance abuse, 16 SIP patients and 54 healthy controls were enrolled in this study. 3T MRI and 18-FDG-PET scanning were acquired.

Results: Gray matter (GM) volume and cerebral metabolism reductions in temporal cortices were observed in all patients compared to healthy controls. Moreover, a distinct pattern of fronto-limbic alterations were found in patients with substance abuse. Specifically, BD patients with substance abuse showed volume reductions in ventrolateral prefrontal cortex, anterior cingulate, insula and thalamus, whereas SIP patients in dorsolateral prefrontal cortex and posterior cingulate. Common alterations in cerebellum and parahippocampus were found in both BD with substance abuse and SIP. Finally, a unique pattern of GM volumes reduction, with concomitant increased of striatal metabolism, were observed in SIP patients.

Conclusions: These findings contribute to shed light on the identification of common and distinct neural markers associated with bipolar psychosis and substance abuse. Future longitudinal studies should explore the effect of single substances of abuse in patients at the first-episode of BD and substanceinduced psychosis.

(c) 2016 Elsevier Masson SAS. All rights reserved.
\end{abstract}

\section{Introduction}

Bipolar disorder (BD) is a chronic psychiatric disorder, characterized by severe disability and high economic burden

\footnotetext{
* Corresponding author at: Department of Neurosciences and Mental Health, Fondazione IRCCS Ca' Granda Ospedale Maggiore Policlinico, via F. Sforza 35, 20122 Milan, Italy.

E-mail address: paolo.brambilla1@unimi.it (P. Brambilla).
}

[1]. The disease encompasses recurring mood swings between episodes of mania, hypomania and depression [2]. About $75 \%$ of patients with an acute manic episode displays psychotic symptoms and comorbid substance abuse [3-5] acting to exacerbate its clinical manifestation [6]. Therefore, several behavioral and genetic studies consistently suggested the clinical relevance of differentiating psychotic and nonpsychotic BD [7,8]. Indeed, psychotic symptoms seem to explain the phenotypic variability of $\mathrm{BD}$ in terms of severity and response to treatment, which in turn, 
Table 1

Q6 Socio-demographic and clinical variables.

\begin{tabular}{|c|c|c|c|c|c|c|}
\hline & BDns patients & BDws patients & SIP patients & $\begin{array}{l}\text { HC } \\
\text { MRI study }\end{array}$ & $\begin{array}{l}\text { HC } \\
\text { PET study }\end{array}$ & Post-hoc results \\
\hline$n$ & 17 & 10 & 16 & 27 & 27 & \\
\hline Age, years (SD) & $38.7(8.2)$ & $35.7(13.2)$ & $25.7(7.3)$ & $34(10)$ & $49.4(11.5)$ & $\begin{array}{l}\text { SIP }<\text { all other groups } \\
\text { All } P<0.05\end{array}$ \\
\hline Gender male/female (SD) & $4 / 13$ & $9 / 1$ & $14 / 2$ & $16 / 11$ & $14 / 13$ & $\mathrm{X} 2=19.3 ; P<0.001$ \\
\hline BPRS total (SD) & $44.7(5.4)$ & $41.7(8.6)$ & $43.5(4.7)$ & $\mathrm{N} / \mathrm{A}$ & $\mathrm{N} / \mathrm{A}$ & $P>0.05$ \\
\hline BPRS-Dep (SD) & $8.5(2.9)$ & $9.1(5.3)$ & $7.2(3.0)$ & $\mathrm{N} / \mathrm{A}$ & $\mathrm{N} / \mathrm{A}$ & $P>0.05$ \\
\hline BPRS-With (SD) & $4.1(1.6)$ & $7.4(4.6)$ & $7.7(2.6)$ & $\mathrm{N} / \mathrm{A}$ & $\mathrm{N} / \mathrm{A}$ & BDns $<$ SIP $P<0.05$ \\
\hline BPRS-Tho (SD) & $7.1(3.5)$ & $9.8(5.5)$ & $11(4.8)$ & $\mathrm{N} / \mathrm{A}$ & $\mathrm{N} / \mathrm{A}$ & BDns $<$ SIP $P<0.05$ \\
\hline BPRS-Act (SD) & $5.4(2.5)$ & $7(3.6)$ & $6.3(3.2)$ & $\mathrm{N} / \mathrm{A}$ & $\mathrm{N} / \mathrm{A}$ & $P>0.05$ \\
\hline BPRS-host (SD) & $6.3(3.3)$ & $8.4(4.1)$ & $9.5(2.5)$ & $\mathrm{N} / \mathrm{A}$ & $\mathrm{N} / \mathrm{A}$ & BDns $<$ SIP $P<0.05$ \\
\hline Age of onset, years (SD) & $25.7(7.0)$ & $25.6(6.5)$ & $21.8(5.1)$ & $\mathrm{N} / \mathrm{A}$ & $\mathrm{N} / \mathrm{A}$ & All $P>0.05$ \\
\hline $\begin{array}{l}\text { Duration of illness, } \\
\text { years (SD) }\end{array}$ & $11.4(7.0)$ & $12.1(8.5)$ & $5.8(7.2)$ & $\mathrm{N} / \mathrm{A}$ & $\mathrm{N} / \mathrm{A}$ & $\begin{array}{l}\mathrm{SIP}<\text { BDws } \\
P<0.05\end{array}$ \\
\hline Substance use, months (SD) & $\mathrm{N} / \mathrm{A}$ & $93.6(71.4)$ & $68.4(50.8)$ & $\mathrm{N} / \mathrm{A}$ & $\mathrm{N} / \mathrm{A}$ & \\
\hline $\begin{array}{l}\text { Drug use by substance } \\
\text { (\% of patients) }\end{array}$ & & $\begin{array}{l}\text { Cannabis: } 6(60 \%) \text {; } \\
\text { cocaine: } 1(10 \%) ; \\
\text { polyabuser: } 3(30 \%)\end{array}$ & $\begin{array}{l}\text { Cannabis: } 7(44 \%) \text {; } \\
\text { cocaine: } 1(6 \%) ; \\
\text { polyabuser: } 8(50 \%)\end{array}$ & $\mathrm{N} / \mathrm{A}$ & $\mathrm{N} / \mathrm{A}$ & \\
\hline Medications & $\begin{array}{l}\text { AC (13); atypical } \\
\text { AP (12); typical } \\
\text { AP (2); AD (3) }\end{array}$ & $\begin{array}{l}\mathrm{AC}(7) ; \text { atypical } \mathrm{AP}(6) \\
\text { typical } \mathrm{AP}(6) ; \mathrm{AD}(0)\end{array}$ & $\begin{array}{l}\text { AC (14); atypical AP (13); } \\
\text { typical AP (13); AD (0) }\end{array}$ & N/A & $\mathrm{N} / \mathrm{A}$ & \\
\hline
\end{tabular}

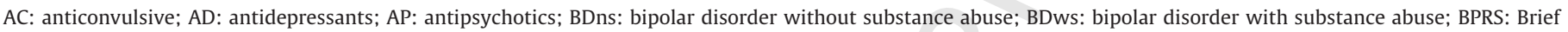

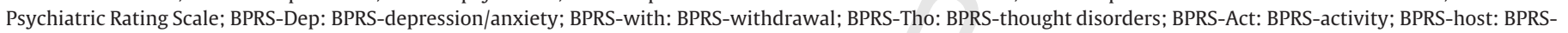
hostility/suspiciousness; HC: healthy controls; SD: standard deviation; SIP: substance-induced psychosis.

further supports the presence of a clinical overlap with schizophrenia [9]. Furthermore, it has been shown that BD patients with a history of psychotic symptoms show a deteriorating course of the disease, poorer outcomes, and enduring cognitive impairment [10]. However, although behavioral and genetic studies consistently support the clinical relevance of differentiating psychotic and nonpsychotic BD [7,8], biological markers associated with these aspects remain poorly investigated. Nonetheless, it is worth remarking that the magnetic resonance imaging (MRI) research reported that psychotic symptoms in BD are associated with reduced gray matter (GM) density and connectivity in several prefrontal, temporal and limbic regions in both adult $[11,12]$ and pediatric [13] BD patients. Similarly, it is still not fully elucidated how the co-occurrence of substance abuse may interact with psychosis in affecting the bipolar brain $[14,15]$. In this context, it is worth noting that the disruptive metabolic and morphological effects of substance abuse have been reported in heavy drug abusers, independently of the drug used, in several brain regions, including prefrontal [16-19], temporal [16] and cerebellar [20] cortices as well as subcortical areas [21]. Nonetheless, the specific neural underpinnings of drug abuse in BD have been explored only by two MRI studies [22,23]. Jarvis et al. [22] showed decreased GM volumes in the fusiform gyrus and increased GM volumes in the caudate and precentral gyrus in $\mathrm{BD}$ with co-occurring abuse disorder, compared to BD without substance abuse. Further, Hassel et al. [23] reported that substance use severity correlated with decreased activation in the prefrontal cortex and in the caudate during an emotional processing task in patients with BD. Finally, the interplay between psychosis and substance abuse in BD has almost been neglected. Interestingly, in the framework of psychosis spectrum, a review of 15 structural MRI studies found that psychotic patients with co-occurrence cannabis use showed decreased GM volumes in the cingulum, the dorsolateral prefrontal cortex (DLPFC) and the cerebellum [24].

In this context, to the best of our knowledge, this study aims for the first time at characterizing the effects of psychosis and substance abuse on morphology and metabolism in BD with fullblown psychotic patients, coupling MRI and positron emission tomography (PET). We hypothesized that substance abuse would determine a specific and more extensive pattern of structural and metabolic dysfunctions in BD and SIP in comparison to BD without substance abuse.

\section{Methods}

\subsection{Participants}

Patients were recruited at the Psychiatric inward of the University Policlinico Hospital of Milan, Italy. It comprised 10 BD type I psychotic patients with substance abuse, 17 BD type I psychotic patients without substance abuse, 16 patients with substance-induced psychosis (SIP); all of them were on stable pharmacological treatment with different psychotropic compounds (Table 1). BD or SIP patients fulfilled the diagnostic criteria of the Diagnostic and Statistical Manual of Mental Disorders, 4th edition, text revision (DSM-IV-TR) [25], based on the Structured Clinical Interview for Diagnosis (SCID-I) [26,27]. All patients were experiencing mild to acute symptomatology at the time of the scanning (mean Brief Psychiatric Rating Scale [BPRS] scores below 45 for all patients). Regardless of the diagnosis, 8 abusers out of 26 were taking only cannabis and 2 out of 26 only cocaine whereas all the others were polyabusers with reported past use of cannabis in combination with cocaine, meta-amphetamine and LSD (16 out of 26). Substance abuse was assessed with the SCID-I, which was a comorbid diagnosis in BD. Moreover, the type of drug, the intensity and the duration of abuse were confirmed with the SCICA [28]. The BPRS was administered to all the patients [29] and the mean scores and standard deviations of the sub-domains of the BPRS are shown in Table 1. We also included a group of healthy controls based on the absence of a personal or family lifetime history of any psychiatric disorder. Two independent samples of 27 healthy controls for the MRI and PET were included for the analyses. Exclusion criteria for all participants were a diagnosis of mental retardation, any current major medical or neurological illness, a history of traumatic head injury with loss of consciousness, and any other Axis I disorders, including alcohol abuse. The study was approved by the local Ethical Committee. Informed consent was obtained for all participants. 


\subsection{Magnetic resonance imaging}

Acquisition parameters: MR images were acquired using a 3Tesla Philips Achieva MRI scanner. All the participants reclined in a supine position on the bed of the scanner and a radio frequency (RF) coil (Bruker NMR Instruments Inc., Fremont, California) was placed over their head. Earplugs and headphones were provided to block background noise. Following a 3-plane gradient echo scan for alignment and localization, a shim procedure was performed to generate a homogeneous, constant magnetic field. A total of 165 contiguous $1-\mathrm{mm}$ sagittal slices extending superiorly from the inferior aspect of the cerebellum to encompass most of the brain were selected from a sagittal localizer scan. A high-resolution T1weighted three-dimensional brain scan was then obtained using a modified driven equilibrium Fourier transform (MDEFT) protocol (repetition time $[\mathrm{TR}]=6.9$, echo time $[\mathrm{TE}]=3.4 \mathrm{msec}$, field of view $[\mathrm{FOV}]=25 \times 25 \times 18.2, \quad 228 \times 227$, flip angle $=8^{\circ}$ ). Precautions were taken to minimize subject motion during the MRI study by instructing subjects to remain still and packing around their heads with foam padding.

\subsection{Positron emission tomography (PET)}

Acquisition parameters: PET scans were obtained with a Biograph Truepoint 64 PET/computed tomography (CT) scanner (Siemens, Erlangen, Germany) at the Nuclear Medicine Department of Fondazione IRCCS Cà Granda Ospedale Maggiore Policlinico in Milan. All patients underwent 18-FDG-PET scanning at rest after intravenous injection of $170 \mathrm{MBq}$. Patients were positioned comfortably in a quiet, dimly lit room several minutes before FDG administration and for at least 30 min during the uptake phase of FDG. They were instructed not to speak, read or be otherwise active. Each acquisition included a CT transmission scan of the head ( $50 \mathrm{mAs}$ lasting $16 \mathrm{~s}$ ) followed by a 3D static emission of $15 \mathrm{~min}$ using a Biograph Truepoint 64 PET/CT scanner (v). PET sections were reconstructed in the form of transaxial images of $128 \times 128$ pixels of $2 \mathrm{~mm}$, using an iterative algorithm, ordered subset expectation maximization, corrected for scatter and for attenuation using density coefficients derived from the low-dose CT scan of the head obtained with the same scanner, with the proprietary software. The resolution of the PET system was 4-5 mm FWHM.

\subsection{Neuroimaging data analysis}

Pre-processing: two different and complementary analyses were performed: a voxel-based morphometry (VBM) analysis and a PET analysis using Statistical Parametric Mapping (SPM12) (http://www.fil.ion.ucl.ac.uk/spm/software/spm12/) implemented in MATLAB R2012b (MathWorks Inc. USA). All the images were co-registered to the Montreal Neurological Institute template, which was then segmented according to GM, white matter and cerebrospinal fluid tissue probability maps. The resulting images were spatially normalized into the MNI space using an affine spatial normalization. For the PET images, the standardized uptake value (SUV) maps have been derived from the original $\left.{ }^{18} \mathrm{~F}\right]$ FDG images. Subsequently, the SUV images have been spatially normalized into the T1-weighted MR images. Finally, MRI and PET images were smoothed with an isotropic Gaussian kernel of $6 \mathrm{~mm}$ full width at half maximum (FWHM) to increase the signal-to-noise ratio and to account for subtle variations in anatomic structures. Before the VBM and PET analyses, we extracted the total intracranial volume using SPM12.

\subsection{Statistical analyses}

For demographic and clinical variables, we performed $\mathrm{Chi}^{2}$ tests for categorical variables and analysis of variance (ANOVA) for quantitative variables (Table 1). For the MRI and PET investigations, we performed a full-factorial analysis of covariance (ANCOVA) with nuisance covariates of age, gender and intracranial volumes. Then, we performed post-hoc analyses using two-sample $t$ tests between the groups (please refer to Tables 2 and 3 with the details of all the contrasts employed in this study for both the VBM and PET analysis). For the VBM analyses, suprathreshold clusters were identified using peak Family Wise Error (pFWE) correction of $P<0.05$ for the ANCOVA together with cluster False Discovery Rate (cFDR) corrected for all post-hoc analyses. For PET analyses, $P<0.005$ uncorrected was considered significant and a minimum cluster size of $440 \mathrm{~mm}^{3}$ was employed. Stereotactic coordinates of the peak maxima of the suprathreshold clusters were converted (http://www.mrc-cbu.cam.ac.uk/Imaging/mnispace.html/) from the Montreal Neurological Institute spatial array (http://www. mni.mcgill.ca/) to that of Talairach and Tournoux [30].

\section{Results}

A total of 10 BD type I psychotic patients with substance abuse, 17 BD type I psychotic patients without substance abuse, 16 SIP patients and 54 healthy controls (27 for PET and 27 for MRI analyses) were enrolled in this study. Due to movement artifacts during the MRI acquisition, two BD type I psychotic patients with substance abuse and one SIP patient were excluded from the study.

\subsection{Analysis of socio-demographic and clinical variables}

For socio-demographic measures, we observed a significant age difference between SIP patients compared to all the other groups $(P<0.05)$. Moreover, regardless of diagnosis, a significant gender difference was detected within all patients' samples $(P<0.05)$. Finally, for clinical variables, no difference was observed in the total scores of the BPRS across all patients' groups. However, BD patients without substance abuse showed lower mean scores compared to SIP patients in three sub-domains of the BPRS, including BPRS-Though Disorders, BPRS-Withdrawal and BPRSHostility/Suspiciousness (all $P<0.05$ ). Further, SIP patients showed a significantly shorter duration of illness compared to BD with substance abuse $(P<0.05)$. Details of socio-demographic and clinical variables are shown in Table 1.

\subsection{Analysis of MRI data}

\subsubsection{Group comparisons}

3.2.1.1. BD patients without substance abuse vs. healthy controls. Compared to healthy controls, BD patients without substance abuse showed abnormally reduced GM volumes in superior temporal gyrus bilaterally (Brodmann area [BA] 38, $P<0.05$ pFWE corrected and $c F D R$ corrected) (Table 2; Figs. 1 and 2).

3.2.1.2. BD patients with substance abuse vs. healthy controls. Compared to healthy controls, BD patients with substance abuse showed abnormally reduced GM volumes in right middle (BA11) and medial (BA25) frontal gyrus, inferior frontal gyrus bilaterally (BA45 and BA47), left superior (BA38) and middle (BA21) temporal gyrus, right fusiform gyrus (BA37), anterior cingulate cortex (ACC) bilaterally (BA32), right posterior cingulate cortex (PCC, BA23), left insula (BA13), parahippocampus bilaterally (BA35 and BA28), right thalamus and left cerebellum $(P<0.05$ pFWE corrected and $c F D R$ corrected).

3.2.1.3. Substance-induced psychosis (SIP) patients vs. healthy controls. Compared to healthy controls, SIP patients showed Q3208 
Table 2

VBM results. Brain regions showing significant reduced GM volumes between the four groups of subjects (all $P<0.05$ pFWE corrected and cFDR corrected).

\begin{tabular}{|c|c|c|c|c|c|c|c|}
\hline Gyrus & $\mathrm{BA}$ & Laterality & $\mathrm{x}$ & $\mathrm{y}$ & $\mathrm{z}$ & Cluster size & z-values \\
\hline \multicolumn{8}{|c|}{ BD without substance abuse $<$ healthy controls } \\
\hline Superior temporal & 38 & Right & 33 & 12 & -28 & 23 & 5.9 \\
\hline Superior temporal & 38 & Left & -36 & 7 & -14 & 26 & 5.2 \\
\hline \multicolumn{8}{|c|}{ BD with substance abuse $<$ healthy controls } \\
\hline Middle frontal & 11 & Right & 0 & 33 & -13 & 194 & 5.9 \\
\hline Inferior frontal & 45 & Left & -59 & 18 & 7 & 32 & 5.9 \\
\hline Inferior frontal & 47 & Right & 33 & 19 & -5 & 84 & 5.6 \\
\hline Medial frontal & 25 & Right & 4 & 3 & -18 & 116 & 5.7 \\
\hline Superior temporal & 38 & Left & -34 & 14 & -31 & 53 & 5.9 \\
\hline Middle temporal & 21 & Left & -55 & -21 & -5 & 62 & 5.6 \\
\hline Fusiform & 37 & Right & 27 & -40 & -13 & 189 & 5.5 \\
\hline Anterior cingulate & 32 & Left & -6 & 33 & 23 & 106 & 6.1 \\
\hline Anterior cingulate & 32 & Right & 9 & 34 & 18 & 46 & 5.5 \\
\hline Posterior cingulate & 23 & Right & 0 & -23 & 33 & 102 & 5.4 \\
\hline Insula & 13 & Left & -42 & -15 & 16 & 48 & 5.1 \\
\hline Parahippocampus & 35 & Left & -30 & -21 & -13 & 1183 & 6.6 \\
\hline Parahippocampus & 28 & Right & 31 & 5 & -19 & 69 & 5.6 \\
\hline Thalamus & - & Right & 19 & -28 & -2 & 1509 & 6.8 \\
\hline Cerebellum & - & Left & -40 & -50 & -38 & 315 & 6.9 \\
\hline \multicolumn{8}{|c|}{ Substance-induced psychosis $<$ healthy controls } \\
\hline Middle frontal & 10 & Right & 43 & 40 & 10 & 92 & 6.8 \\
\hline Middle frontal & 10 & Left & -28 & 42 & 21 & 106 & 6.0 \\
\hline Middle frontal & 46 & Right & 43 & 40 & 20 & 50 & 6.0 \\
\hline Middle frontal & 46 & Left & -46 & 29 & 22 & 74 & 5.5 \\
\hline Superior frontal & 6 & Left & -6 & 9 & 59 & 174 & 6.5 \\
\hline Middle frontal & 6 & Right & 40 & -3 & 54 & 81 & 5.5 \\
\hline Middle frontal & 11 & Right & 4 & 27 & -14 & 538 & 6.4 \\
\hline Middle frontal & 9 & Right & 30 & 34 & 37 & 28 & 5.5 \\
\hline Middle frontal & 9 & Left & -40 & 22 & 36 & 26 & 5.4 \\
\hline Medial frontal & 8 & Left & -4 & 30 & 41 & 27 & 5.2 \\
\hline Middle temporal & 21 & Left & -56 & -19 & -8 & 509 & 6.9 \\
\hline Middle temporal & 21 & Right & 62 & -9 & -13 & 232 & 6.0 \\
\hline Superior temporal & 38 & Right & -22 & 13 & -30 & 60 & 5.2 \\
\hline Inferior temporal & 20 & Right & 53 & -10 & -30 & 62 & 5.2 \\
\hline Posterior cingulate & 23 & Left & -1 & -23 & 33 & 3589 & 6.9 \\
\hline Parahippocampus & 28 & Left & -22 & -19 & -8 & 16,138 & 7.5 \\
\hline Parahippocampus & 36 & Right & 30 & -41 & -3 & 55 & 5.4 \\
\hline Cerebellum & - & Left & -40 & -48 & -37 & 644 & 7.7 \\
\hline Cerebellum & - & Right & 22 & -47 & -42 & 234 & 6.8 \\
\hline Putamen & - & Right & 34 & -15 & 13 & 83 & 5.9 \\
\hline Caudate & - & Left & -2 & 18 & 1 & 40 & 5.7 \\
\hline \multicolumn{8}{|c|}{$\begin{array}{l}\text { Substance-induced psychosis }<\text { BD with substance abuse } \\
\text { No sopratreshold clusters }\end{array}$} \\
\hline \multicolumn{8}{|c|}{$\begin{array}{l}\text { Substance-induced psychosis }<\text { BD without substance abuse } \\
\text { No sopratreshold clusters }\end{array}$} \\
\hline \multicolumn{8}{|c|}{ BD with substance abuse $<$ BD without substance abuse } \\
\hline Parahippocampus & 35 & Left & -28 & -18 & -14 & 33 & 5.1 \\
\hline Thalamus & - & Right & 10 & -20 & 9 & 75 & 5.4 \\
\hline Cerebellum & - & Left & -27 & -39 & -22 & 58 & 5.5 \\
\hline \multicolumn{8}{|c|}{$\begin{array}{l}\text { BD without substance abuse }<\text { BD with substance abuse } \\
\text { No suprathreshold clusters }\end{array}$} \\
\hline \multicolumn{8}{|c|}{$\begin{array}{l}\text { BD without substance abuse }<\text { substance-induced psychosis } \\
\text { No suprathreshold clusters }\end{array}$} \\
\hline \multicolumn{8}{|c|}{ BD with substance abuse $<$ substance-induced psychosis } \\
\hline No suprathreshold & & & & & & & \\
\hline
\end{tabular}

VBM: voxel-based morphometry; GM: Gray matter; pFWE: peak Family Wise Error; cFDR: cluster False Discovery Rate; BD: bipolar disorder; BA: Brodmann area.

abnormally reduced GM volumes in left superior frontal gyrus (BA6), middle frontal gyrus bilaterally (BA10, BA11, BA9, BA46 and BA6), medial frontal gyrus (BA8), middle temporal gyrus bilaterally (BA21), right superior (BA38) and inferior (BA20) temporal gyrus, left PCC (BA23), parahippocampus bilaterally (BA28 and BA36), cerebellum bilaterally and right putamen and caudate $(P<0.05$, pFWE corrected and cFDR corrected).

3.2.1.4. BD patients with substance abuse vs. BD patients without substance abuse. BD patients with substance abuse showed reduced GM volumes in left parahippocampus (BA35), right thalamus and left cerebellum compared to BD patients without substance abuse $(P<0.05$ pFWE corrected and cFDR corrected).

\subsection{Analysis of PET data}

\subsubsection{Group comparisons}

3.3.1.1. BD patients without substance abuse vs. healthy controls. BD patients without substance abuse had abnormally decreased GM metabolism in the left middle temporal gyrus (BA21) and inferior occipital gyrus (BA19) (Table 3; Figs. 3 and 4). Additionally, BD patients without substance abuse showed increased metabolism in right postcentral gyrus (BA3), right ACC (BA32) and left thalamus compared to healthy controls (all $P<0.005$ uncorrected).

3.3.1.2. BD patients with substance abuse vs. healthy controls. Compared to healthy controls, BD patients with substance abuse had 
Table 3

PET results. Brain regions showing significant GM metabolic dysfunctions between the four groups of subjects (all $P<0.005$ uncorrected).

\begin{tabular}{|c|c|c|c|c|c|c|c|}
\hline Gyrus & $\mathrm{BA}$ & Laterality & $\mathrm{x}$ & $\mathrm{y}$ & $\mathrm{z}$ & Cluster size & z-values \\
\hline \multicolumn{8}{|c|}{ BD without substance abuse $<$ healthy controls } \\
\hline Middle temporal & 21 & Left & -58 & -48 & -3 & 1048 & 4.7 \\
\hline Inferior occipital & 19 & Left & -36 & -79 & -4 & 640 & 4.7 \\
\hline \multicolumn{8}{|c|}{ BD without substance abuse $>$ healthy controls } \\
\hline Postcentral & 3 & Right & 9 & -32 & 68 & 2144 & 5.3 \\
\hline Anterior cingulate & 32 & Right & 17 & 34 & 13 & 4405 & 5.6 \\
\hline Thalamus & - & Left & -25 & -23 & 10 & 2965 & 6.5 \\
\hline \multicolumn{8}{|c|}{ Substance-induced psychosis $<$ healthy controls } \\
\hline Superior temporal & 42 & Left & -62 & -23 & 10 & 1895 & 6.2 \\
\hline Superior temporal & 41 & Right & 48 & -30 & 11 & 972 & 4.7 \\
\hline Inferior temporal & 20 & Right & 53 & -57 & -13 & 1456 & 4.6 \\
\hline Inferior temporal & 37 & Left & -41 & -68 & -3 & 839 & 5.3 \\
\hline \multicolumn{8}{|c|}{ Substance-induced psychosis $>$ healthy controls } \\
\hline Putamen & - & Right & 25 & -4 & 22 & 2032 & 5.3 \\
\hline Putamen & - & Left & -19 & -8 & -4 & 2303 & 5.4 \\
\hline Caudate & - & Right & 39 & -29 & -3 & 639 & 4.5 \\
\hline Cerebellum & - & Right & 10 & -51 & -27 & 2214 & 5.0 \\
\hline \multicolumn{8}{|c|}{ BD with substance abuse $<$ healthy controls } \\
\hline Medial frontal & 10 & Left & -1 & 46 & 12 & 440 & 4.4 \\
\hline Superior temporal & 42 & Left & -62 & -23 & 10 & 1895 & 6.2 \\
\hline Superior temporal & 41 & Right & 43 & -30 & 11 & 972 & 4.7 \\
\hline Inferior temporal & 20 & Right & 53 & -57 & -13 & 1456 & 4.6 \\
\hline Inferior temporal & 37 & Left & -41 & -68 & -3 & 839 & 4.8 \\
\hline \multicolumn{8}{|c|}{ BD with substance abuse $>$ healthy controls } \\
\hline Thalamus & - & Right & 15 & -9 & 5 & 634 & 4.7 \\
\hline Cerebellum & - & Right & 10 & -53 & -27 & 4691 & 5.8 \\
\hline \multicolumn{8}{|c|}{ Substance-induced psychosis $<$ BD without substance abuse } \\
\hline Posterior cingulate & 29 & Left & -4 & -41 & 11 & 446 & 3.4 \\
\hline \multicolumn{8}{|c|}{ BD with substance abuse $<$ BD without substance abuse } \\
\hline Posterior cingulate & 29 & Right & 1 & -41 & 11 & 487 & 3.3 \\
\hline \multicolumn{8}{|c|}{$\begin{array}{l}\text { Substance-induced psychosis }>\text { BD with substance abuse } \\
\text { No sopratreshold clusters }\end{array}$} \\
\hline \multicolumn{8}{|c|}{$\begin{array}{l}\text { Substance-induced psychosis }<\text { BD with substance abuse } \\
\text { No sopratreshold clusters }\end{array}$} \\
\hline \multicolumn{8}{|c|}{$\begin{array}{l}\text { Substance-induced psychosis }>\text { BD without substance abuse } \\
\text { No sopratreshold clusters }\end{array}$} \\
\hline \multicolumn{8}{|c|}{$\begin{array}{l}\text { BD with substance abuse }>\text { BD without substance abuse } \\
\text { No sopratreshold clusters }\end{array}$} \\
\hline
\end{tabular}

PET: positron emission tomography; VBM: voxel-based morphometry; GM: Gray matter; BD: bipolar disorder; BA: Brodmann area.

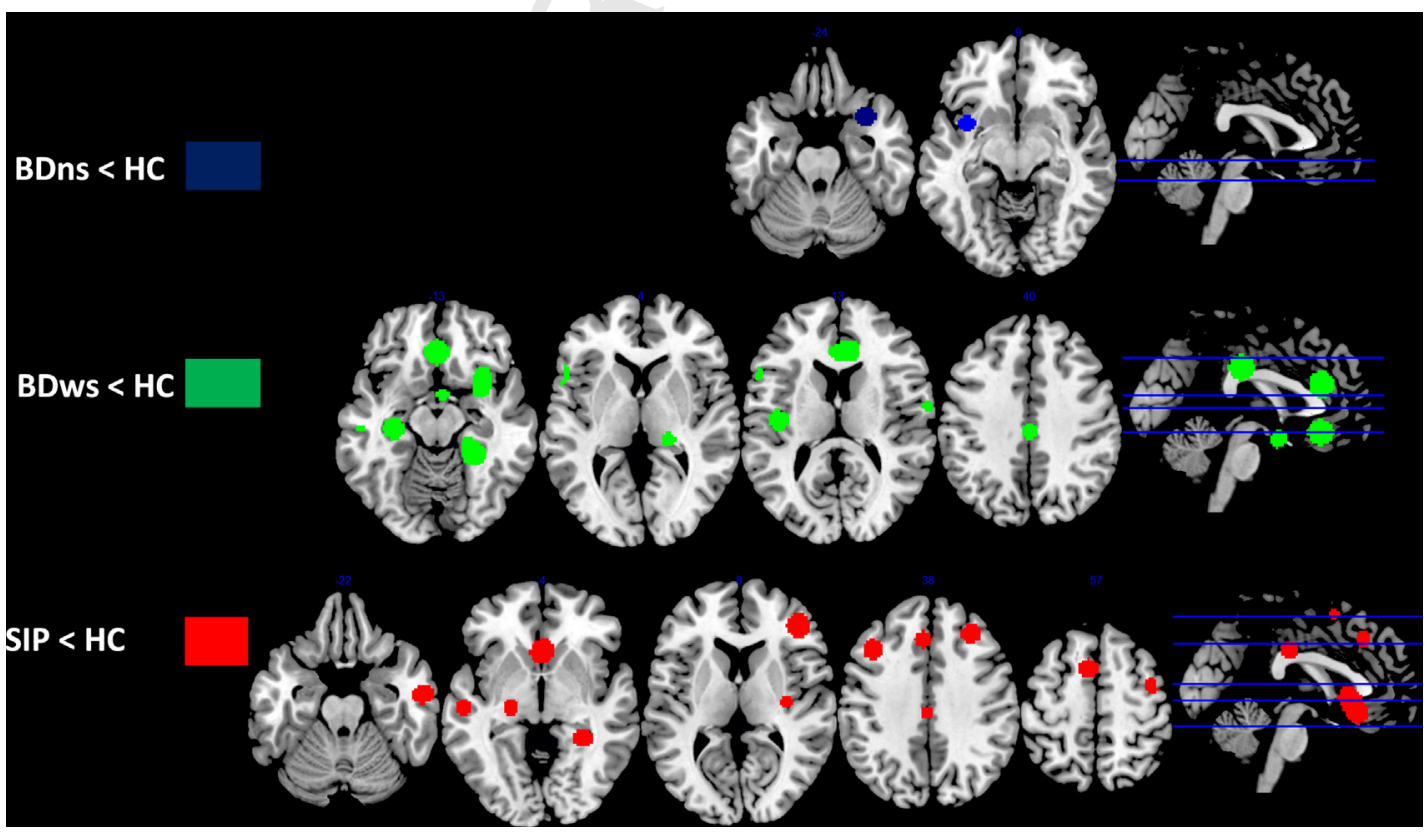

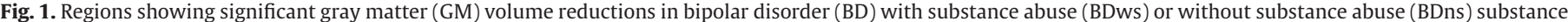

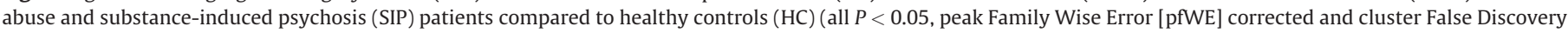
Rate [cFDR] corrected).

Please cite this article in press as: Altamura AC, et al. Structural and metabolic differentiation between bipolar disorder with psychosis and substance-induced psychosis: An integrated MRI/PET study. European Psychiatry (2016), http://dx.doi.org/10.1016/j.eurpsy.2016.09.009 


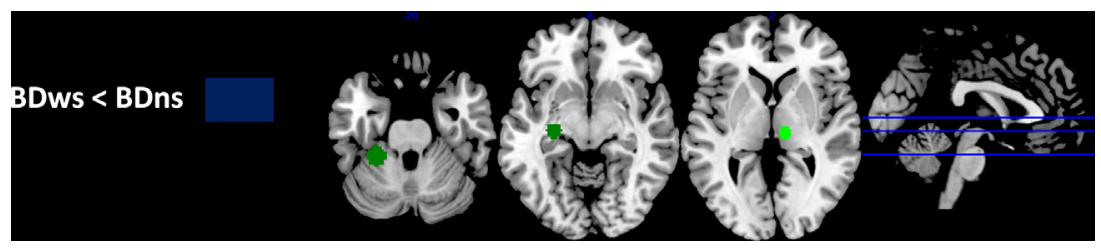

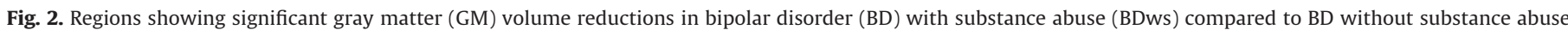
(BDns) $(P<0.05$, peak Family Wise Error [pfWE] corrected and cluster False Discovery Rate [cFDR] corrected).

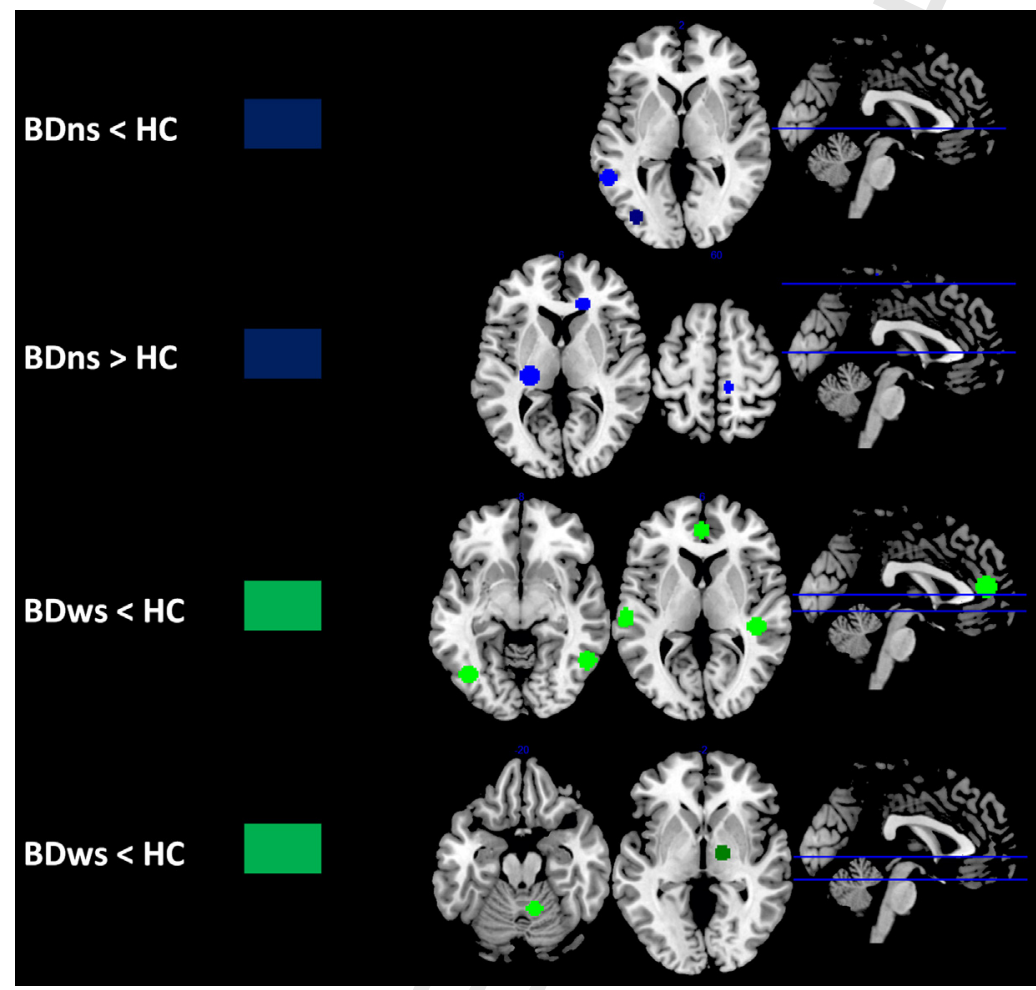

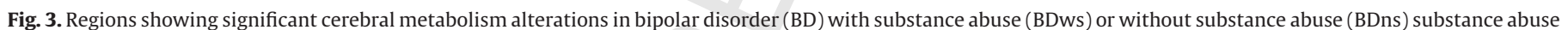
patients compared to healthy controls (HC) (all $P<0.005$, uncorrected).

abnormally decreased GM metabolism in superior temporal gyrus (BA41 and BA42) and inferior temporal gyrus (BA20 and BA37) bilaterally. In addition, BD patients with substance abuse showed increased metabolism in right thalamus and right cerebellum (all $P<0.005$ uncorrected).

3.3.1.3. SIP patients vs. healthy controls. Compared to healthy controls, SIP patients had abnormally decreased GM metabolism in superior (BA41 and BA42) and inferior (BA20 and BA37) temporal gyrus bilaterally. Moreover, they showed increased GM metabolism in putamen bilaterally, right caudate, right hippocampus and right cerebellum (all $P<0.005$ uncorrected).

3.3.1.4. SIP patients vs. BD patients without substance abuse. Compared to BD patients without substance abuse, SIP patients showed decreased metabolism in left posterior cingulate (BA29) $(P<0.005$ uncorrected $)$.

3.3.1.5. BD patients with substance abuse vs. BD patients without substance abuse. Compared to $\mathrm{BD}$ patients without substance abuse, BD patients with substance abuse showed decreased metabolism in right posterior cingulate (BA29) $(P<0.005$ uncorrected $)$.

\section{Discussion}

Our group analysis, for both MRI and PET analyses, showed significant abnormalities in GM volumes and cerebral metabolism in the three groups of patients compared to healthy controls in an extended network, encompassing frontal, temporal, limbic, cerebellar and striatal areas. Interestingly, the multiple pairwise comparisons showed four key findings. First, a common pattern of structural and metabolic brain alterations between BD patients with and without substance abuse and SIP patients within temporal regions. Second, a diagnosis specific pattern of brain alterations in the substance abusers within a fronto-limbic network. Particularly, BD patients with substance abuse showed $\mathrm{GM}$ volumes reduction in the ventrolateral prefrontal cortex (VLPFC), anterior cingulate cortex (ACC), thalamus and insula, whereas SIP patients had significant GM volumes reduction in dorsolateral prefrontal cortex (DLPFC), and posterior cingulate cortex (PCC). Additionally, SIP patients reported abnormal cerebral metabolism in PCC compared to the other two group of patients. Third, subjects with substance abuse, either BD or SIP, had a unique pattern of GM volume reduction in parahippocampal and cerebellar regions. Finally, SIP patients showed GM volumes reduction coupled with cerebral metabolism alterations in
266 


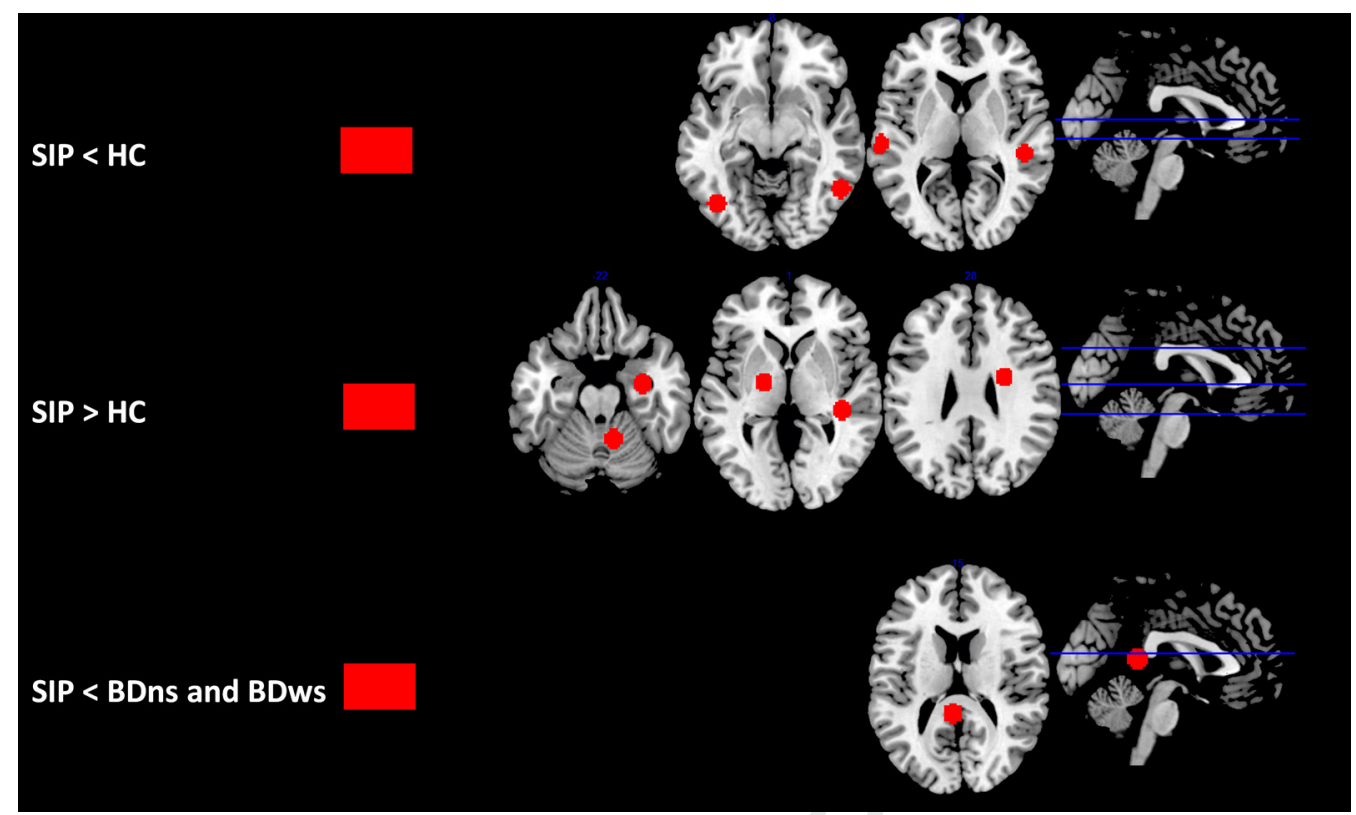

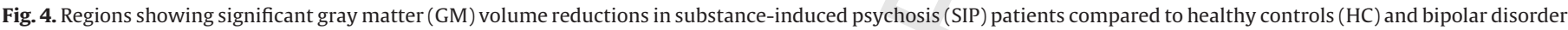

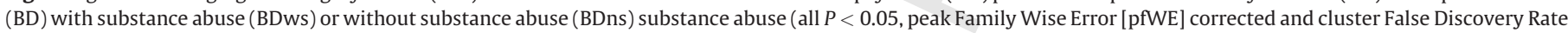
[cFDR] corrected).

putamen and caudate compared to healthy controls (for VBM results see Table 2, Figs. 1 and 2; for PET results see Table 3, Figs. 3 and 4).

\subsection{Temporal abnormalities: a neurobiological marker of psychosis?}

Regardless of the diagnosis, patients revealed GM volume and cerebral metabolism alterations in temporal regions compared to healthy controls. However, the extent of these abnormalities differed across diagnosis. Indeed, while BD patients without substance abuse showed GM volume reductions only in the superior temporal gyrus (BA38), BD patients with substance abuse and SIP patients showed a wider temporal alterations encompassing the superior, middle and inferior temporal gyri. In this regard, it should be mentioned that the superior temporal gyrus is involved in auditory and language processing [31] and theory of mind [32], abilities that are notably abnormal in individuals with psychosis [31,33-36]. Therefore, it is plausible that this common brain dysfunction in the superior temporal gyrus, transversally present in all the three groups of patients with psychosis, could be considered a biological marker of psychosis [37]. Specifically, for BD patients without substance abuse, the superior temporal gyrus reductions are in line with previous studies, but not all [38-40], showing thinning $[41,42]$ as well as altered metabolism [43] in BD. Indeed, the superior temporal gyrus has been reported to be part of a neural network implicated in emotional processing [44], a core function that has been consistently found to be impaired in BD [45].

Furthermore, our results suggest that substance abuse exacerbates structural and metabolic impairments in the temporal cortex. Indeed, both BD patients with substance of abuse and SIP patients showed a similar and a more extensive pattern of brain dysfunction in this area in comparison with BD patients without substance of abuse. Although there is no evidence of GM and metabolic abnormalities in temporal cortices in BD patients with substance abuse, several studies reported an association with GM volume reductions in this area in substance dependent individuals compared to healthy controls [46,47]. Similarly, the reduction in temporal regions in SIP patients might be in line with brain dysfunctions observed in recent years by MRI studies in schizophrenia [48]. Indeed, the theoretical model of schizophrenia proposed that psychotic and cognitive symptoms result from alterations in fronto-temporal and subcortical networks [4956]. Therefore, these common patterns of brain dysfunctions further support the hypothesis that substance-induced psychosis might lie within a "grey" overlapping zone between schizophrenia and BD within a psychosis continuum $[9,57]$. In conclusion, although the presence of a significant overlapping of temporal alterations in the three groups when compared to healthy controls, our results demonstrated that substance abuse has negative effects on brain structures and functions by determining wider temporal GM and metabolic dysfunctions.

\subsection{Differential fronto-limbic involvement in $B D$ patients with} substance abuse and SIP patients: a possible biomarker of substance abuse?

Compared to healthy controls, patients with substance abuse had diagnosis specific bilateral abnormalities in fronto-limbic regions. In particular, BD patients with substance abuse showed GM volumes reduction in VLPFC (BA45 and BA47), ACC (BA32), insula (BA13) and thalamus. These regions have been consistently reported to be altered in BD patients [45,58-61] but the lack of GM abnormalities found in our sample of BD patients without substance abuse suggests that drug abuse might have accelerated and deepen the appearance of morphological abnormalities usually reported in BD. As a matter of fact, VLPFC and ACCcognitive impairments were found in chronic stimulants abusers [62] and they seem to be associated with reward-based cognitive inflexibility and risky decision making in Internet addictions [63].

In contrast, SIP patients had more prominent GM volumes reduction in DLPFC (BA9, BA10 and BA46) and in PCC (BA23 and BA29) as well as decreased cerebral metabolism in PCC compared to BD patients with and without substance abuse. Our results are in line with previous literature showing DLPFC volume reduction in patients abusing cocaine [64,65], methamphetamine [66], and heroin [67]. Interestingly, a large body of evidence reported the role of DLPFC in working memory and attention $[47,62]$ as well as 
in self-control and motivated behaviors [62], abilities that have been reported to characterize individuals with drug addiction or dependence [46]. Similarly, PCC is a core region of the default mode network (DMN) in humans [68] and alterations have been described in chronic abusers [24,69,70]. Finally, deficits in the DLPFC and in the PCC have been largely described in schizophrenia [71,72], supporting the hypothesis that SIP lies between schizophrenia and BD, as mentioned previously. Hence, a deeper insight in SIP might help to understand the notion of psychosis continuum.

\subsection{Cerebellar and parahippocampal alterations: a unique pattern of brain dysfunction characterizing only psychotic patients with substance abuse?}

Volume and metabolic reductions of cerebellar regions were detected in both BD patients with substance abuse and SIP patients compared to healthy controls. Additionally, BD patients with substance abuse showed significant GM volume reduction in cerebellar volumes compared to BD patients without substance abuse. In recent years, the role of the cerebellum has been widely studied in psychiatric illnesses, including BD [73], and is thought to be involved in the regulation of emotion and cognition $[74,75]$. However, with regards to $\mathrm{BD}$, the available literature reported contradictory findings, with decreased GM volumes $[76,77]$ as well as no differences $[78,79]$ in cerebellar regions in BD patients compared to healthy controls. In contrast, the effect of drug addiction, mainly cannabis and cocaine, on cerebellar integrity has been consistently suggested $[80,81]$. Indeed, several strands of evidence have reported that the systematic exposure to these drugs causes molecular and structural/functional alterations in the cerebellum [82-85].

Furthermore, BD patients with substance abuse and SIP patients also share a common GM volume decrease in parahippocampus compared to healthy controls. For BD patients specifically, structural [86] and functional [87] alterations in the parahippocampus have been consistently suggested due to its involvement in emotional processing [87]. Additionally, a single-photon emission computed tomography study also reported a significant inverse association between resting regional blood flow in parahippocampal gyrus and severity of depressive mood, further sustaining its involvement in mood disorders [88]. Finally, independent MRI studies suggested the involvement of this structure in both addiction [89] and psychosis [90-92].

In conclusion, taken together these findings suggest that the exposure to drugs, regardless of the diagnosis, increases the susceptibility to cerebellar and parahippocampal pathology, which might be related to the direct neurotoxic effect of drugs on GM density.

\subsection{Striatal alterations: a unique feature of Substance-Induced Psychosis patients?}

The direct comparison between SIP patients and healthy controls also showed a significant GM volumes reduction with concomitant increased metabolic activity in both the putamen and caudate. These regions are part of the striatum which has been reported to be connected with both cortical and midbrain dopamine cell body regions [93]. Moreover, cannabis and cocaine affect the mesolimbic dopamine system, including putamen and caudate [94-97], which is crucial to the reward-processing and drug addiction [98,99]. Indeed, previous studies underlined that a dysfunction in the reward system relate to increased risk of substance abuse [100-102]. Specifically, it has been found altered mesocorticolimbic connectivity in abusers of methamphetamine [103], cannabis [104] and in offspring of abusers [105].
Therefore, our results suggest that striatal alterations are closely linked to the consumption of drugs, which act to disrupt the reward system that is evident in SIP patients.

\subsection{Limitations}

Some limitations to our study should be taken into account when interpreting the results. First, the relatively small sample size might have limited the statistical power of our analyses, although it is in line with PET and MRI studies investigating substance abuse $[22,23,69]$. Second, patients were not fully matched for age and gender. However, we included these variables as covariates in the statistical analyses. Third, we cannot exclude the impact of psychotropic drugs on our results since all patients were taking mood stabilizers and/or antipsychotics. Fourth, it was not possible to explore the effects of only one substance of abuse, since the majority of the abusers were taking cannabis and cocaine. Fifth, the inclusion of two independent samples of healthy controls for the MRI and PET analyses might have affected the comparison of the results across these two techniques. Finally, the cross-sectional design employed in this study did not allow for the investigation of GM volumes and metabolic changes over time.

\section{Conclusions}

To the best of our knowledge, this is the first study trying to integrate metabolic and morphological data to study the interplay between psychosis and substance abuse in BD. We provide evidence of common and diagnosis specific abnormalities between the three groups of patients compared to healthy controls. Specifically, we found volume and metabolic reductions in temporal regions in all patients in comparison to healthy controls. However, more extensive patterns of abnormalities were found in patients with substance abuse, independently of the diagnosis. Furthermore, distinct GM volume and metabolic dysfunctions were observed in fronto-limbic regions in BD with substance abuse and in SIP, with common alterations in cerebellum and parahippocampus. Finally, structural and metabolic striatal abnormalities were found only in SIP patients, supporting the disruption of the dopamine reward system in psychosis, induced by the abuse of recreational substances.

Taken as a whole, our findings help in leading towards the identification of specific neural markers associated with bipolar psychosis and substance abuse. Future longitudinal studies are needed to corroborate our results by identifying the direct effect of a single substance of abuse in patients at the first-episode of BD and substance-induced psychosis.

\section{Disclosure of interest}

The authors declare that they have no competing interest.

\section{Acknowledgments}

We would like to thank all the participants involved in this study and Mr. Martin Jones for carefully proofreading the English Language. This study was partially supported by grants from the Italian Ministry of Health to PB (GR-2010-2316745).

\section{References}

[1] Bowden CL. Strategies of reduced misdiagnosis of bipolar disorder. Psych Serv 2001;52:51-5.

[2] Grande I, Berk M, Birmaher B, Vieta E. Bipolar disorder. Lancet 2016;387(10027):1561-72.

[3] Cassidy F, Ahearn EP, Carroll BJ. Substance abuse in bipolar disorder. Bipolar Disord 2001;3(4):181-8. 
[4] Arias F, Szerman N, Vega P, Mesías B, Basurte I, Rentero D. Bipolar disorde and substance use disorders. Madrid study on the prevalence of dual disorders/pathology. Adicciones. doi: 10.20882/adicciones.782.

[5] Gage SH, Hickman M, Zammit S. Association between cannabis and psychosis: epidemiologic evidence. Biol Psychiatry 2016;79(7):549-56.

[6] Goodwin F, Jamison K. Manic-depressive illness: bipolar disorders and recurrent depression, 2nd ed., New York: Oxford University Press; 2007.

[7] Marneros A, Röttig S, Röttig D, Tscharntke A, Brieger P. Bipolar I disorder with mood-incongruent psychotic symptoms: a comparative longitudinal study. Eur Arch Psychiatry Clin Neurosci 2009;259(3):131-6

[8] Tao R, Cousijn H, Jaffe AE, Burnet PW, Edwards F, Eastwood SL, et al. Expression of ZNF804A in human brain and alterations in schizophrenia, bipolar disorder, and major depressive disorder: a novel transcript fetally regulated by the psychosis risk variant rs1344706. JAMA Psychiatry 2014;71(10):111220.

[9] Keshavan MS, Morris DW, Sweeney JA, Pearlson G, Thaker G, Seidman LJ, et al. A dimensional approach to the psychosis spectrum between bipolar disorder and schizophrenia: the Schizo-Bipolar Scale. Schizophr Res 2011;133(13):250-4.

[10] Simonsen C, Sundet K, Vaskinn A, Birkenaes AB, Engh JA, Faerden A, et al. Neurocognitive dysfunction in bipolar and schizophrenia spectrum disorders depends on history of psychosis rather than diagnostic group. Schizophr Bull 2011;37(1):73-83.

[11] Tost H, Ruf M, Schmäl C, Schulze TG, Knorr C, Vollmert C, et al. Prefrontaltemporal gray matter deficits in bipolar disorder patients with persecutory delusions. J Affect Disord 2010;120(1-3):54-61.

[12] James A, Hough M, James S, Burge L, Winmill L, Nijhawan S, et al. Structural brain and neuropsychometric changes associated with pediatric bipolar disorder with psychosis. Bipolar Disord 2011;13(1):16-27.

[13] Anticevic A, Savic A, Repovs G, Yang G, McKay DR, Sprooten E, et al. Ventra anterior cingulate connectivity distinguished nonpsychotic bipolar illness from psychotic bipolar disorder and schizophrenia. Schizophr Bull 2015;41(1):133-43.

[14] Schaffer A, Cairney J, Veldhuizen S, Kurdyak P, Cheung A, Levitt A. A population-based analysis of distinguishers of bipolar disorder from major depressive disorder. J Affect Disord 2010;125(1-3):103-10.

[15] Parkar SR, Ramanathan S, Nair N, Batra SA, Adarkar SA, Kund P, et al. Are the effects of cannabis dependence on glucose metabolism similar to schizophrenia? An FDG PET understanding. Indian J Psychiatry 2011;53(1):13-20.

[16] Aoki Y, Orikabe L, Takayanagi Y, Yahata N, Mozue Y, Sudo Y, et al. Volum reductions in frontopolar and left perisylvian cortices in methamphetamine induced psychosis. Schizophr Res 2013;147(2-3):355-61.

[17] Kuepper R, Ceccarini J, Lataster J, van Os J, van Kroonenburgh M, van Gerven JM, et al. Delta-9-tetrahydrocannabinol-induced dopamine release as a function of psychosis risk: 18F-fallypride positron emission tomography study. PLoS One 2013;8(7):e70378.

[18] Cheng H, Skosnik PD, Pruce BJ, Brumbaugh MS, Vollmer JM, Fridberg DJ, et al. Resting-state functional magnetic resonance imaging reveals distinct brain activity in heavy cannabis users - a multi-voxel pattern analysis. J Psychopharmacol 2014;28(11):1030-40.

[19] Howells FM, Uhlmann A, Temmingh H, Sinclair H, Meintjes E, Wilson D, et al. (1)H-magnetic resonance spectroscopy ((1)H-MRS) in methamphetamine dependence and methamphetamine induced psychosis. Schizophr Res 2014;153(1-3):122-8.

[20] Cohen M, Rasser PE, Peck G, Carr VJ, Ward PB, Thompson PM, et al. Cerebellar grey-matter deficits, cannabis use and first-episode schizophrenia in adolescents and young adults. Int J Neuropsychopharmacol 2012;15(3):297307.

[21] Battistella G, Fornari E, Annoni JM, Chtioui H, Dao K, Fabritius M, et al. Longterm effects of cannabis on brain structure. Neuropsychopharmacology 2014;39(9):2041-8.

[22] Jarvis K, DelBello MP, Mills N, Elman I, Strakowski SM, Adler CM. Neuroanatomic comparison of bipolar adolescents with and without cannabis use disorders. J Child Adolesc Psychopharmacol 2008;18(6):557-63.

[23] Hassel S, Almeida JR, Frank E, Versace A, Nau SA, Klein CR, et al. Prefronta cortical and striatal activity to happy and fear faces in bipolar disorder is associated with comorbid substance abuse and eating disorder. J Affect Disord 2009;118(1-3):19-27.

[24] Rapp C, Bugra H, Riecher-Rössler A, Tamagni C, Borgwardt S. Effects of cannabis use on human brain structure in psychosis: a systematic review combining in vivo structural neuroimaging and post mortem studies. Curr Pharm Des 2012;18(32):5070-80.

[25] American Psychiatric Association. Diagnostic and Statistical Manual of Mental Disorders (DSM-5), 4th text rev. ed., Washington, DC: American Psychiatric Press; 2000.

[26] First MB, Spitzer RL, Gibbon M, Williams JBW. Structured clinical interview for DSM-IV-TR Axis I disorders, research version, patient edition (SCID-I/P). New York, NY: Biometrics Research, New York State Psychiatric Institute; 2002.

[27] First MB, Spitzer RL, Gibbon M, Williams JBW. Structured clinical interview for DSM-IV-TR Axis I disorders, research version, non-patient edition (SCID-I/ NP). New York, NY: Biometrics Research, New York State Psychiatric Institute; 2002.

[28] Achenbach TM, Rescorla LA. Manual for the ASEBA school-age forms \& profiles. Burlington, VT: University of Vermont, Research Center for Children, Youth, \& Families; 2001.
[29] Overall JE, Gorham DR. The Brief Psychiatric Rating Scale. Psychol Rep 1962;10:799-812.

[30] Talairach J, Tournoux P. Co-planar stereotaxic atlas of the human brain. New York, NY: Thieme; 1988.

31] Anderson JE, Wible CG, McCarley RW, Jakab M, Kasai K, Shenton ME. An MRI study of temporal lobe abnormalities and negative symptoms in chronic schizophrenia. Schizophr Res 2002;58(2-3):123-34.

[32] Beauchamp MS. The social mysteries of the superior temporal sulcus. Trends Cogn Sci 2015:19(9):489-90.

[33] Sanfilipo M, Lafargue T, Rusinek H, Arena L, Loneragan C, Lautin A, et al. Volumetric measure of the frontal and temporal lobe regions in schizophrenia: relationship to negative symptoms. Arch Gen Psychiatry 2000;57(5):471-80.

[34] Gur RE, Turetsky BI, Cowell PE, Finkelman C, Maany V, Grossman RI, et al. Temporolimbic volume reductions in schizophrenia. Arch Gen Psychiatry 2000;57(8):769-75.

[35] Brüne M, Brüne-Cohrs U. Theory of mind-evolution, ontogeny, brain mechanisms and psychopathology. Neurosci Biobehav Rev 2006;30(4):437-55.

[36] Pettersson-Yeo W, Benetti S, Frisciata S, Catani M, Williams SC, Allen P, et al. Does neuroanatomy account for superior temporal dysfunction in early psychosis? A multimodal MRI investigation. I Psychiatry Neurosci 2015;40(2):100-7.

[37] Tosato S, Bellani M, Bonetto C, Ruggeri M, Perlini C, Lasalvia A, et al. Is neuregulin 1 involved in determining cerebral volumes in schizophrenia? Preliminary results showing a decrease in superior temporal gyrus volume. Neuropsychobiology 2012;65(3):119-25.

[38] Brambilla P, Harenski K, Nicoletti M, Sassi RB, Mallinger AG, Frank E, et al. MRI investigation of temporal lobe structures in bipolar patients. J Psychiatr Res 2003;37(4):287-95.

[39] Kasai K, Shenton ME, Salisbury DF, Onitsuka T, Toner SK, Yurgelun-Todd D, et al. Differences and similarities in insular and temporal pole MRI gray matter volume abnormalities in first-episode schizophrenia and affective psychosis. Arch Gen Psychiatry 2003;60(11):1069-77.

[40] Adler CM, DelBello MP, Jarvis K, Levine A, Adams J, Strakowski SM. Voxelbased study of structural changes in first-episode patients with bipolar disorder. Biol Psychiatry 2007;61(6):776-81.

[41] Elvsåshagen T, Westlye LT, Bøen E, Hol PK, Andreassen OA, Boye B, et al. Bipolar II disorder is associated with thinning of prefrontal and temporal cortices involved in affect regulation Bipolar Disord 2013;15(8):855-64.

[42] Lyoo IK, Hwang J, Sim M, Dunn BJ, Renshaw PF. Advances in magnetic resonance imaging methods for the evaluation of bipolar disorder. CNS Spectr 2006;11(4):269-80.

[43] Osuch EA, Ketter TA, Kimbrell TA, George MS, Benson BE, Willis MW, et al. Regional cerebral metabolism associated with anxiety symptoms in affective disorder patients. Biol Psychiatry 2000;48(10):1020-3.

[44] Mitchell RL, Elliott R, Barry M, Cruttenden A, Woodruff PW. Neural response to emotional prosody in schizophrenia and in bipolar affective disorder. $\mathrm{Br} \mathrm{J}$ Psychiatry 2004:184:223-30.

[45] Townsend J, Altshuler LL. Emotion processing and regulation in bipolar disorder: a review. Bipolar Disord 2012;14(4):326-39.

[46] Ersche KD, Jones PS, Williams GB, Turton AJ, Robbins TW, Bullmore ET. Abnormal brain structure implicated in stimulant drug addiction. Science 2012;335(6068):601-4

[47] Cummings JL. Neuropsychiatric manifestations of right hemisphere lesions. Brain Lang 1997;57(1):22-37.

[48] Bakhshi K, Chance SA. The neuropathology of schizophrenia: a selective review of past studies and emerging themes in brain structure and cytoarchitecture. Neuroscience 2015;303:82-102.

[49] Hirayasu Y, Shenton ME, Salisbury DF, Dickey CC, Fischer IA, Mazzoni P, et al. Lower left temporal lobe MRI volumes in patients with first-episode schizophrenia compared with psychotic patients with first-episode affective disorder and normal subjects. Am J Psychiatry 1998;155(10):1384-91.

[50] Buchanan RW, Pearlson G. Prefrontal cortex, structural analysis: segmenting the prefrontal cortex. Am J Psychiatry 2004;161(11):1978.

[51] Assaf M, Rivkin PR, Kuzu CH, Calhoun VD, Kraut MA, Groth KM, et al. Abnormal object recall and anterior cingulate overactivation correlate with formal thought disorder in schizophrenia. Biol Psychiatry 2006;59(5):452-9.

[52] Goghari VM, Sponheim SR, MacDonald 3rd AW. The functional neuroanatomy of symptom dimensions in schizophrenia: a qualitative and quantitative review of a persistent question. Neurosci Biobehav Rev 2010:34(3):468-86.

[53] Hugdahl K, Løberg EM, Nygård M. Left temporal lobe structural and functional abnormality underlying auditory hallucinations in schizophrenia. Front Neurosci 2009;3(1):34-45.

[54] Bassett DS, Bullmore ET. Human brain networks in health and disease. Curr Opin Neurol 2009;22(4):340-7.

[55] Horn H, Federspiel A, Wirth M, Müller TJ, Wiest R, Wang JJ, et al. Structural and metabolic changes in language areas linked to formal thought disorder. Br J Psychiatry 2009;194(2):130-8.

[56] Zhang W, Deng W, Yao L, Xiao Y, Li F, Liu J, et al. Brain structural abnormalities in a group of never-medicated patients with long-term schizophrenia. Am J Psychiatry 2015;172(10):995-1003.

[57] Altamura AC, Goikolea JM. Differential diagnoses and management strategies in patients with schizophrenia and bipolar disorder. Neuropsychiatr Dis Treat 2008:4(1):311-7.

[58] Fornito A, Yücel M, Wood SJ, Bechdolf A, Carter S, Adamson C, et al. Anterior cingulate cortex abnormalities associated with a first psychotic episode in bipolar disorder. Br J Psychiatry 2009;194(5):426-33. 
[59] Kronhaus DM, Lawrence NS, Williams AM, Frangou S, Brammer MJ, Williams SC, et al. Stroop performance in bipolar disorder: further evidence for abnormalities in the ventral prefrontal cortex. Bipol Disord 2006;8(1):28-39.

[60] Blumberg HP, Leung HC, Skudlarski P, Lacadie CM, Fredericks CA, Harris BC. A functional magnetic resonance imaging study of bipolar disorder: state- and trait-related dysfunction in ventral prefrontal cortices. Arch Gen Psychiatry 2003;60(6):601-9.

[61] Frangou S, Kington J, Raymont V, Shergill SS. Examining ventral and dorsal prefrontal function in bipolar disorder: a functional magnetic resonance imaging study. Eur Psychiatry 2008;23(4):300-8.

[62] Goldstein RZ, Volkow ND. Dysfunction of the prefrontal cortex in addiction: neuroimaging findings and clinical implications. Nat Rev Neurosci 2011;12(11):652-69.

[63] Seok JW, Lee KH, Sohn S, Sohn JH. Neural substrates of risky decision making in individuals with Internet addiction. Aust N Z J Psychiatry 2015; 49(10):923-32.

[64] Franklin TR, Acton PD, Maldjian JA, Gray JD, Croft JR, Dackis CA, et al. Decreased gray matter concentration in the insular, orbitofrontal, cingulate, and temporal cortices of cocaine patients. Biol Psychiatry 2002:51:134-42.

[65] Matochik JA, London ED, Eldreth DA, Cadet JL, Bolla KI. Frontal cortical tissue composition in abstinent cocaine abusers: a magnetic resonance imaging study. Neuroimage 2003;19(3):1095-102.

[66] Schwartz DL, Mitchell AD, Lahna DL, Luber HS, Huckans MS, Mitchell SH, et al. Global and local morphometric differences in recently abstinent methamphetamine- dependent individuals. Neuroimage 2010;50(4):1392-401.

[67] Yuan Y, Zhu Z, Shi J, Zou Z, Yuan F, Liu Y, et al. Gray matter density negatively correlates with duration of heroin use in young lifetime heroin-dependent individuals. Brain Cogn 2009;71(3):223-8.

[68] Raichle ME, MacLeod AM, Snyder AZ, Powers WJ, Gusnard DA, Shulman GL. A default mode of brain function. Proc Natl Acad Sci U S A 2001:98(2):676-82.

[69] Dragogna F, Mauri MC, Marotta G, Armao FT, Brambilla P, Altamura AC. Brain metabolism in substance-induced psychosis and schizophrenia: a preliminary PET study. Neuropsychobiology 2014;70(4):195-202.

[70] Bednarski SR, Zhang S, Hong KI, Sinha R, Rounsaville BJ, Li CS. Deficits in default mode network activity preceding error in cocaine-dependent individuals. Drug Alcohol Depend 2011;119(3):e51-7.

[71] Zhou Y, Ma X, Wang D, Qin W, Zhu J, Zhuo C, et al. The selective impairment of resting-state functional connectivity of the lateral subregion of the frontal pole in schizophrenia. PLoS One 2015;10(3):e0119176.

[72] Karbasforoushan H, Woodward ND. Resting-state networks in schizophrenia. Curr Top Med Chem 2012;12(21):2404-14.

[73] Phillips JR, Hewedi DH, Eissa AM, Moustafa AA. The cerebellum and psychiatric disorders. Front Public Health 2015;3:66.

[74] Schutter DJ, van Honk J. The cerebellum in emotion regulation: a repetitive transcranial magnetic stimulation study. Cerebellum 2009;8(1):28-34.

[75] Singer T, Seymour B, O'Doherty J, Kaube H, Dolan RJ, Frith CD. Empathy for pain involves the affective but not sensory components of pain. Science 2004;303(5661):1157-62.

[76] Brambilla P, Harenski K, Nicoletti M, Mallinger AG, Frank E, Kupfer DJ, et al. MRI study of posterior fossa structures and brain ventricles in bipolar patients. J Psychiatr Res 2001:35(6):313-22.

[77] Laidi C, d'Albis MA, Wessa M, Linke J, Phillips ML, Delavest M, et al. Cerebellar volume in schizophrenia and bipolar I disorder with and without psychotic features. Acta Psychiatr Scand 2015;131(3):223-33.

[78] Mills NP, Delbello MP, Adler CM, Strakowski SM. MRI analysis of cerebellar vermal abnormalities in bipolar disorder. Am J Psychiatry 2005;162(8):1530-2.

[79] Sani G, Chiapponi C, Piras F, Ambrosi E, Simonetti A, Danese E, et al. Gray and white matter trajectories in patients with bipolar disorder. Bipolar Disord 2016;18(1):52-62.

[80] Vazquez-Sanroman D, Leto K, Cerezo-Garcia M, Carbo-Gas M, Sanchis-Segura C, Carulli D, et al. The cerebellum on cocaine: plasticity and metaplasticity. Addict Biol 2015;20(5):941-55.

[81] Steinmetz AB, Edwards CR, Vollmer JM, Erickson MA, O'Donnell BF, Hetrick WP, et al. Examining the effects of former cannabis use on cerebellumdependent eyeblink conditioning in humans. Psychopharmacology (Berl) 2012;221(1):133-41.

[82] Palomino A, Pavón FJ, Blanco-Calvo E, Serrano A, Arrabal S, Rivera P, et al. Effects of acute versus repeated cocaine exposure on the expression of endocannabinoid signaling-related proteins in the mouse cerebellum. Front Integr Neurosci 2014;8:22.

[83] Moreno-López L, Perales JC, van Son D, Albein-Urios N, Soriano-Mas C, Martinez-Gonzalez JM, et al. Cocaine use severity and cerebellar gray matter are associated with reversal learning deficits in cocaine-dependent individuals. Addict Biol 2015;20(3):546-56.

[84] Anderson CM, Maas LC, Frederick BD, Bendor JT, Spencer TJ, Livni E, et al. Cerebellar vermis involvement in cocaine-related behaviors. Neuropsychopharmacology 2006;31(6):1318-26.

[85] Sim ME, Lyoo IK, Streeter CC, Covell J, Sarid-Segal O, Ciraulo DA, et al. Cerebellar gray matter volume correlates with duration of cocaine use in cocainedependent subjects. Neuropsychopharmacology 2007;32(10):2229-37.

[86] Ha TH, Ha K, Kim JH, Choi JE. Regional brain gray matter abnormalities in patients with bipolar II disorder: a comparison study with bipolar I patients and healthy controls. Neurosci Lett 2009;456(1):44-8.

[87] Delvecchio G, Fossati P, Boyer P, Brambilla P, Falkai P, Gruber O, et al. Common and distinct neural correlates of emotional processing in bipolar disorder and major depressive disorder: a voxel-based meta-analysis of functional magnetic resonance imaging studies. Eur Neuropsychopharmacol 2012;22(2):100-13.

[88] Perico CA-M, Skaf CR, Yamada A, et al. Relationship between regional cerebral blood flow and separate symptom clusters of major depression: a singlephoton emission computed tomography study using statistical parametric mapping. Neurosci Lett 2005;384(3):265270.

[89] Matochik JA, Eldreth DA, Cadet JL, Bolla KI. Altered brain tissue composition in heavy marijuana users. Drug Alcohol Depend 2005;77(1):23-30.

[90] Prasad KM, Rohm BR, Keshavan MS. Parahippocampal gyrus in first-episode psychotic disorders: a structural magnetic resonance imaging study. Prog Neuropsychopharmacol Biol Psychiatry 2004;28(4):651-8.

[91] Kawasaki Y, Maeda Y, Urata K, Higashima M, Yamaguchi N, Suzuki M, et al. A quantitative magnetic resonance imaging study of patients with schizophrenia. Eur Arch Psychiatry Clin Neurosci 1993;242(5):268-72.

[92] Shenton ME, Kikinis R, Jolesz FA, Pollak SD, LeMay M, Wible CG, et al. Abnormalities of the left temporal lobe and thought disorder in schizophrenia. A quantitative magnetic resonance imaging study. N Engl J Med 1992;327(9):604-12.

[93] Haber SN, Knutson B. The reward circuit: linking primate anatomy and human imaging. Neuropsychopharmacol 2010;35(1):4-26.

[94] Adinoff B. Neurobiologic processes in drug reward and addiction. Harv Rev Psychiatry 2004;12(6):305-20.

[95] Volkow ND, Gillespie H, Mullani N, Tancredi L, Grant C, Valentine A, et al. Brain glucose metabolism in chronic marijuana users at baseline and during marijuana intoxication. Psychiatry Res 1996;67(1):29-38.

[96] Volkow ND, Wang GJ, Fowler JS, Hitzemann R, Angrist B, Gatley SJ, et al. Association of methylpheni- date-induced craving with changes in right striato-orbitofrontal metabolism in cocaine abusers: implications in addiction. Am J Psychiatry 1999;156(1):19-26.

[97] Oleson EB, Cheer JF. A brain on cannabinoids: the role of dopamine release in reward seeking. Cold Spring Harb Perspect Med 2012;2(8):a012229.

[98] Breiter HC, Gollub RL, Weisskoff RM, Kennedy DN, Makris N, Berke JD, et al. Acute effects of cocaine on human brain activity and emotion. Neuron 1997;19(3):591-611.

[99] Kobza S, Bellebaum C. Processing of action- but not stimulus-related prediction errors differs between active and observational feedback learning. Neuropsychologia 2015;66:75-87.

[100] Garner BR, Godley SH, Funk RR, Dennis ML, Smith JE, Godley MD. Exposure to Adolescent Community Reinforcement Approach treatment procedures as a mediator of the relationship between adolescent substance abuse treatment retention and outcome. J Subst Abuse Treat 2009;36(3):252-64.

[101] Hommer DW, Bjork JM, Gilman JM. Imaging brain response to reward in addictive disorders. Ann N Y Acad Sci 2011;1216:50-61.

[102] Probst CC, van Eimeren T. The functional anatomy of impulse control disorders. Curr Neurol Neurosci Rep 2013;13(10):386.

[103] Kohno M, Morales AM, Ghahremani DG, Hellemann G, London ED. Risky decision making, prefrontal cortex, and mesocorticolimbic functional connectivity in methamphetamine dependence. JAMA Psychiatry 2014;71(7):812-20.

[104] Yip SW, DeVito EE, Kober H, Worhunsky PD, Carroll KM, Potenza MN. Pretreatment measures of brain structure and reward-processing brain function in cannabis dependence: an exploratory study of relationships with abstinence during behavioral treatment. Drug Alcohol Depend 2014;140: $33-41$.

[105] Akyuz N, Kekatpure MV, Liu J, Sheinkopf SJ, Quinn BT, Lala MD, et al. Structural brain imaging in children and adolescents following prenatal cocaine exposure: preliminary longitudinal findings. Dev Neurosci 2014;36(3-4):316-28. 